\title{
Effect of Pile Foundation on Natural Frequency of Soil Layer
}

\author{
*Shirgir V., Ghanbari A.; \\ Department of Civil Engineering, Kharazmi University, \\ Tehran, Iran \\ Mohammad Amiri A., Derakhshandi A.; \\ Faculty of Engineering, Islamic Azad University, Science and \\ Research Branch, Tehran, Iran \\ Received: 26 Aug 2013 \\ Revised: 30 Dec 2014
}

\begin{abstract}
Free vibration of soil often occurs during earthquakes. Since the vibration caused by earthquake does not have (steady state harmonic vibration) continuity, the alluvium vibrates with its natural frequency between two natural seismic waves. This study evaluates the effect of piles on the period of free vibration of a soil layer using numerical method. In the first stage, using analytical equations for calculation of vibration period of a soil layer and a column with continuous mass, the results were analyzed by the software. In the second step, piles with the same dimensions and distance were added step by step, and the vibration period for the soil layer with piles was calculated. The friction or floating effects of the piles on alluvial soil vibration period was also examined. The results show that as the number of piles increases, the differences between the results of one dimensional
\end{abstract}

\footnotetext{
*Corresponding author v.shirgir@gmail.com
} 
analysis of alluvium soil and the results of the software become different, and this creates the need for specific arrangements for seismic analysis of this kind of alluvium (with inserted piles). The results also suggest that end-bearing piles have a greater effect on alluvial soil vibration period, and with increased amount of the floating of these piles, these effects decline.

Keywords: free vibration period, piles in alluvium, end-bearing and friction piles, numerical method

\section{Introduction}

Studies show that soft sedimentary deposits reinforce geological movements resulting from the earthquake whose intensification happens in case of the synchronization of the earthquake period with the period of the structure, leading to damages [1]. So, the more accurate and realistic is the forecast of the period of soil alluvium, the safer the design of a structure against seismic loads. Piles are used as foundations of the structures built in a soft soil to improve soil properties and transfer structural loads to lower more stable layers. Increased strength of high structures sensitive to side loading in the foundations is another characteristic of such foundations. Interaction issues are generally considered in phenomena in which two objects with different hardness are next to one another. This issue is shown in pile foundations with regard to the difference of the material of the pile construction and the surrounding soil [1]. As a result of this 
phenomenon and different responses of objects, distribution of forces and anchors is different in soil and the construction. Displacement and vibrations resulting from seismic loads are not spared either. Studies show that the behavior of soil reinforced by group piles depends on the parameters such as the relative hardness of the soil to pile, the number of group piles, the ratio between the length of the pile and the earthquake wave length, and the distance between the piles. When reinforcing the weak soil (small relative hardness, few number of the piles in the group, and relatively small wavelength), the piles have no effect on the behavior of the soil, and in this mode, soil movement in the field of freedom can be used for the dynamic analysis of the pile [2]. This article set to examine the effect of piles on the period of free vibration of a soil layer using numerical method. This is done step by step by adding piles with the same distance and dimension and measuring the vibration period of the soil layer and piles. The endbearing or floating effects of piles on vibration period of alluvial soil are also discussed.

\section{Literature review}

Kamatchi et al. (2010) examined the effects of the depth of alluvium soil layers on the performance of buildings. The researchers studied some important parameters of earthquakes on constructions, suggesting that, considering the changes in the depth of the soil layer where the constructions is located, a major change happens in the base shear constructions and location change. Similarly, with changes in 
the depth of alluvium layer on which the construction is located, the construction response can vary in terms of construction performance (elasto plastic, etc.). The studies clearly show that due to the design spectrum proposed by seismic regulations that only observe the upper layer of soil (upper 30 meters), as being effected by soil reinforcement, the seismic performance of a building may not be predicted confidently. This reflects the fact that further investigations must consider the effects of the site type and the depth of the soil layer that have a significant effect on the building performance [3].

Rovithis et al. (2011) performed a one-dimensional and analytical study on the response of a non-homogeneous soil layer. The researchers studied the shear wave propagation in heterogeneous environments and evaluated the results by changing the amount of heterogeneity. The studies show that for soils with low shear modulus on the ground surface, increased heterogeneity factor leads to the transfer of lower frequency mode vibrations and thus increases the seismic response. This may have significant practical implications for input movements of low frequency content [4]. Stamatopoulos (2014) studied the effects of non-permanent loads on seismic response of alluvial soil, indicating that soil preload reduces the period of the free vibration of the alluvial soil. These effects depend on the depth of the bedrock and alluvial soil type [5]. Sumio Sawada (2004) presented a semi-analytical equation to calculate the period of the free vibration of laminated sediments. Alluvial soil acts as a filter for seismic waves 
transmitted from the bedrock to the surface. Due to the cleaning effect, the frequency and amplitude of seismic wave and also the motor characteristics of the earth response are affected. Hence, investigating the effect of this on the seismic response of constructions and the alluvium is important [6].

Chenari et al. (2012) studied the effect of shear modulus heterogeneity on the behavior of the response of natural alluvial deposits, suggesting that random heterogeneity has significant effects on the dynamic properties of natural alluvial material, and ignoring it would lead to overestimation of the fundamental frequency of alluvial deposits [7]. Ruiz and Saragoni (2011) investigated the free vibration of an alluvial soil during great earthquakes. They showed that during great earthquakes, the alluvial soil experiences its natural vibration many times through frequency [8]. Hadjian (2002) proposed an equation to calculate the free vibration frequency and vibration mode of multi-layer soil [9]. Christos Vrettos (2013) analytically examined the effects of hardness of different layers of alluvial soil on free vibration frequency, considering the nonlinear influences of alluvial materials. Some studies developed a transform matrix, and by comparing its results with finite element software reported satisfactory results [10]. By increasing the number of piles in a pile group, the period quotient of the system decreases. In other words, an increase in the number of the piles in a pile group increases the stiffness of the system whereas its period decreases [11]. Findings suggest that elements (like piles) that cause changes in the material and soil texture 
change the vibration characteristics of alluvial soil. The effect of piles on the vibration characteristics of an alluvial layer has received less attention, requiring more research to precisely examine its dimensions.

\section{Verification of the results of finite element software}

In the first step of validation, period of the free vibration of an alluvium with approximate dimensions of $120^{m} \times 30^{m}$ was considered. The modeling of the alluvium in the software is twodimensional, and the results are compared with the values of analytic equation (1). The alluvial material properties are presented in Table 1. Figure 1 shows a schematic representation of the modeled alluvium. Table 1 shows characteristics of the studied materials for this part.

Equation 1 offers the value of the fundamental period of a homogeneous alluvium on a rigid bed rock using a one-dimensional analysis [1]:

$$
T=\frac{4 H_{S}}{V_{S}}
$$

Where: $H_{s}$ : depth of alluvium (m), $V_{s}$ : velocity of shear wave passing of alluvium material $(\mathrm{m} / \mathrm{sec})$.

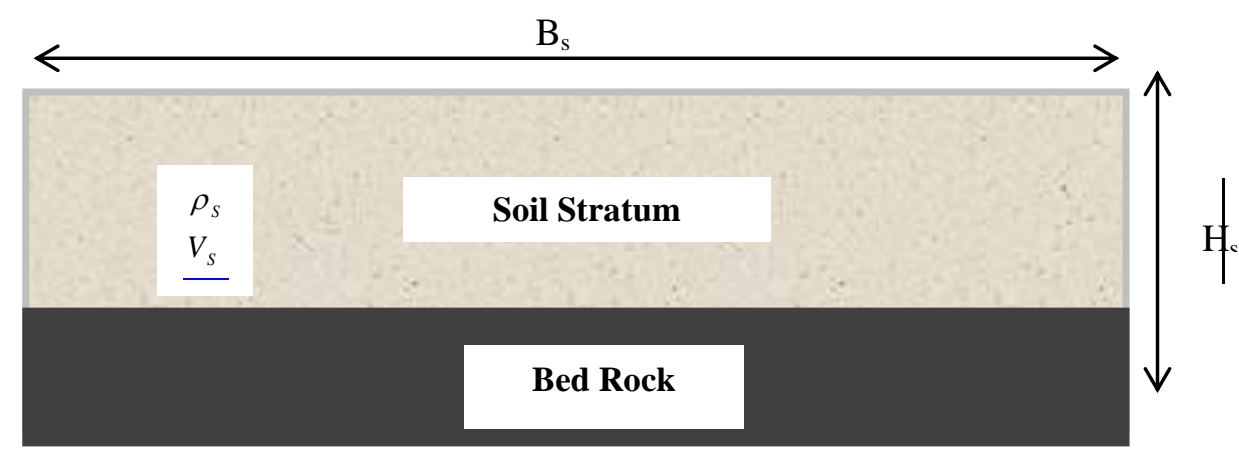

Figure 1. Schematic view of a layer of alluvial soil on rigid bed 
Table 1. Characteristics of the material studied for validation of the results of free vibration of alluvial soil

\begin{tabular}{ccccccc}
\hline $\begin{array}{c}\text { Material } \\
\text { Number }\end{array}$ & $\mathrm{E}_{\mathrm{S}}\left(\mathrm{N} / \mathrm{m}^{2}\right)$ & $\rho_{\mathrm{S}}\left(\mathrm{kg} / \mathrm{m}^{3}\right)$ & $\mathrm{Vs}(\mathrm{m} / \mathrm{s})$ & $\mathrm{Gs}\left(\mathrm{N} / \mathrm{m}^{2}\right)$ & $v_{\mathrm{s}}$ & $\mathrm{H}_{\mathrm{S}}(\mathrm{m})$ \\
\hline 1 & $2.4 \mathrm{E}+07$ & 1900 & 70 & $9.3 \mathrm{E}+06$ & 0.3 & 30 \\
2 & $4.9 \mathrm{E}+07$ & 1900 & 100 & $1.9 \mathrm{E}+07$ & 0.3 & 30 \\
3 & $2.0 \mathrm{E}+08$ & 1900 & 200 & $7.6 \mathrm{E}+07$ & 0.3 & 30 \\
4 & $4.4 \mathrm{E}+08$ & 1900 & 300 & $1.7 \mathrm{E}+08$ & 0.3 & 30 \\
5 & $7.9 \mathrm{E}+08$ & 1900 & 400 & $3.0 \mathrm{E}+08$ & 0.3 & 30 \\
6 & $1.2 \mathrm{E}+09$ & 1900 & 500 & $4.8 \mathrm{E}+08$ & 0.3 & 30 \\
7 & $1.8 \mathrm{E}+09$ & 1900 & 600 & $6.8 \mathrm{E}+08$ & 0.3 & 30 \\
8 & $2.4 \mathrm{E}+09$ & 1900 & 700 & $9.3 \mathrm{E}+08$ & 0.3 & 30 \\
9 & $3.2 \mathrm{E}+09$ & 1900 & 800 & $1.2 \mathrm{E}+09$ & 0.3 & 30 \\
10 & $4.0 \mathrm{E}+09$ & 1900 & 900 & $1.5 \mathrm{E}+09$ & 0.3 & 30 \\
11 & $4.9 \mathrm{E}+09$ & 1900 & 1000 & $1.9 \mathrm{E}+09$ & 0.3 & 30 \\
\hline
\end{tabular}

To ensure integration, the results of the application of three types of mesh with dimensions $0.5^{m}, 0.3^{m}, 0.1^{m}$ were studied. The results show that the mesh with dimension $0.5^{m}$ has good accuracy (Table 2). Table 2 shows the convergence of the numerical results and optimum mesh size. So, 0.5 meter mesh size was chosen to reduce the analysis time.

Table 2. changes of the software results with different mesh sizes

\begin{tabular}{|cc|}
\hline Mesh $_{(\mathbf{m})}$ & $\mathbf{T}_{\text {Abaqus (sec) }}$ \\
\hline 0.5 & 0.266248 \\
\hline 0.3 & 0.266241 \\
\hline 0.1 & 0.266234 \\
\hline
\end{tabular}




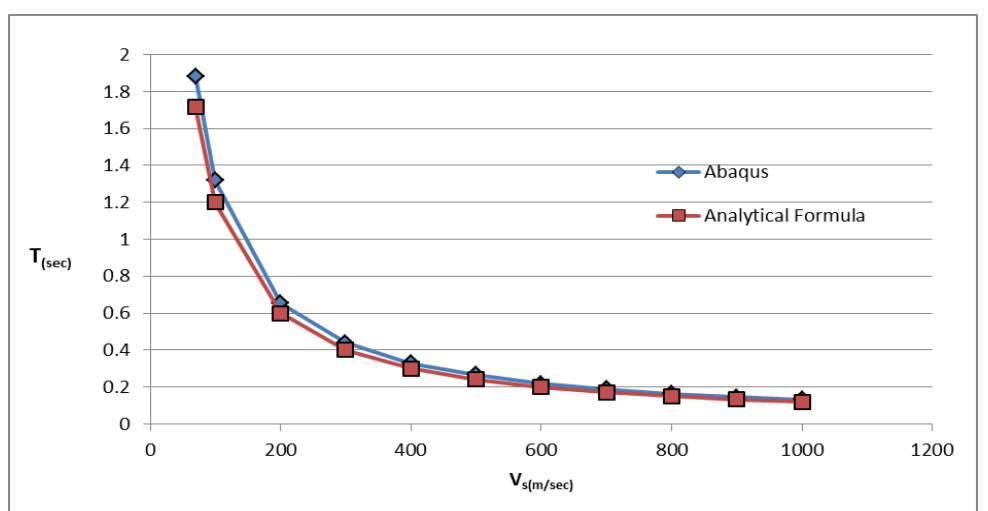

Figure 2. Comparison of the results of the software and one-dimensional analytical equation

To ensure the accuracy of the modeling results by finite element software (ABAQUS), comparison is made between the results of this application and the equations that we are convinced of the correctness of their results. To start a prismatic column (continuous mass), it was modeled with a fixed base. Then, the values of the main period of the output construction fluctuation of the software were obtained and compared with the results of the relationship provided in the Regulation Standard No. 2800 (appendix 4) [12]. Table 3 shows the modeling characteristics and the properties of materials for this construction. According to IC-2800(1995), the time for the main period of the fluctuations of the prism with uniform mass and section in height can obtained by the following equation [12]:

$$
T=1.79 l^{2} \sqrt{\frac{q}{g E I}}
$$

Where: 1: the prism length, q: unit weight of prism length, g: gravity acceleration, E: elasticity modulus, I: moment of inertia. 
Table 3. Specifications of materials for comparison of software and the equation provided in the Regulation Standard No. 2800

\begin{tabular}{ccccccccc}
\hline $\begin{array}{c}\text { Material } \\
\text { Number }\end{array}$ & $\mathbf{r}_{(\mathbf{m})}$ & $\mathbf{l}_{(\mathbf{m})}$ & $\mathbf{q}_{(\mathbf{k g} / \mathbf{m})}$ & $\mathbf{I}_{(\mathbf{m})}{ }^{4}$ & $\mathbf{E}_{(\mathrm{N} / \mathbf{m} 2)}$ & $\mathbf{g}_{(\mathbf{m} / \mathbf{s} 2)}$ & $\mathbf{A}_{(\mathbf{m})}^{2}$ & $\boldsymbol{\rho}_{(\mathbf{k g} / \mathbf{m})}{ }^{\mathbf{2}}$ \\
\hline 1 & 0.5 & 10 & 785.375 & 0.049086 & $2.00 \mathrm{E}+10$ & 9.81 & 0.785375 & 1000 \\
2 & 0.5 & 10 & 1570.75 & 0.049086 & $2.00 \mathrm{E}+10$ & 9.81 & 0.785375 & 2000 \\
3 & 0.5 & 10 & 3926.875 & 0.049086 & $2.00 \mathrm{E}+10$ & 9.81 & 0.785375 & 5000 \\
4 & 0.5 & 10 & 7853.75 & 0.049086 & $2.00 \mathrm{E}+10$ & 9.81 & 0.785375 & 10000 \\
5 & 0.5 & 10 & 11780.63 & 0.049086 & $2.00 \mathrm{E}+10$ & 9.81 & 0.785375 & 15000 \\
\hline
\end{tabular}

年.

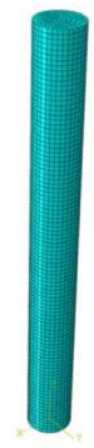

Figure 3: A view of the prism mass, modeled in the software

Table (4) shows the comparison of the results between the two methods. As the results show, modeling in finite element software mentioned previously has proper precision for the calculation of the main period of the constructions.

\section{Numerical study}

At First, the sensitivity of results to dimension changes in the application of alluvial soil is examined. For this purpose, a model of alluvial soil with constant material properties, but different aspects of modeling, and the results for the models were compared. The software 
results for various widths $\left(B_{S}\right)$ and constant heights $\left(H_{S}\right)$ do not differ (Table 5), and they are of the same value as the analytical equation 1 . So, it can be concluded that the results provided by the software are independent of the model width, and only depend on the characteristics of materials and the height of the soil layer. Evaluating the height changes of the alluvial soil and shear wave velocity with respect to the software results, it is clear that software results and analytical equation (1) have good agreements (Figure 4).

Table 4. Comparison of the results obtained by the software and the Regulation Standard No. 2800 equation for prismatic mass

\begin{tabular}{|c|c|c|c|c|c|c|c|c|c|}
\hline $\begin{array}{c}\mathbf{r} \\
(\mathbf{m})\end{array}$ & $\begin{array}{c}1 \\
(\mathrm{~m})\end{array}$ & $\mathbf{q}_{(\mathrm{kg} / \mathrm{m})}$ & $I_{\left(m^{4}\right)}^{4}$ & $\mathbf{E}_{(\mathrm{N} / \mathrm{m} 2)}$ & $\begin{array}{c}\mathbf{g} \\
(\mathrm{m} / \mathrm{s} 2) \\
\end{array}$ & $\mathbf{A}_{(\mathbf{m})}{ }^{2}$ & $\begin{array}{c}\rho_{3} \\
\left(\mathrm{~kg} / \mathrm{m}^{2}\right)\end{array}$ & $\mathbf{T}(\mathbf{2 8 0 0})_{(\mathrm{sec})}$ & $\begin{array}{c}\text { T(Abaqu } \\
\text { s) })_{(\mathrm{sec})}\end{array}$ \\
\hline $\begin{array}{l}0 . \\
5\end{array}$ & 10 & 785.375 & 0.049086 & $2.00 \mathrm{E}+10$ & 9.81 & 0.785375 & 1000 & 0.051116784 & $\begin{array}{c}0.0513932 \\
12\end{array}$ \\
\hline $\begin{array}{l}0 . \\
5\end{array}$ & 10 & 1570.75 & 0.049086 & $2.00 \mathrm{E}+10$ & 9.81 & 0.785375 & 2000 & 0.072290049 & $\begin{array}{c}0.0726806 \\
12\end{array}$ \\
\hline $\begin{array}{c}0 . \\
5\end{array}$ & 10 & $\begin{array}{c}3926.87 \\
5\end{array}$ & 0.049086 & $2.00 \mathrm{E}+10$ & 9.81 & 0.785375 & 5000 & 0.114300603 & $\begin{array}{c}0.1149208 \\
54\end{array}$ \\
\hline $\begin{array}{c}0 . \\
5\end{array}$ & 10 & 7853.75 & 0.049086 & $2.00 \mathrm{E}+10$ & 9.81 & 0.785375 & 10000 & 0.161645463 & $\begin{array}{c}0.1625238 \\
81\end{array}$ \\
\hline
\end{tabular}

Table 5. Material characteristics for comparison of the results of software and analytical equation to study the effects of alluvial soil

\begin{tabular}{ccccccccc}
\hline $\begin{array}{c}\text { Number of } \\
\text { materials }\end{array}$ & $\mathbf{V}_{\mathbf{S}(\mathbf{m} / \mathbf{S e c})}$ & $\mathbf{E}_{\mathbf{S}\left(\mathbf{k g} / \mathbf{m}^{2}\right)}$ & $\mathbf{v}_{\mathbf{S}}$ & $\mathbf{H}_{\mathbf{S}(\mathbf{m})}$ & $\boldsymbol{\rho}_{\mathbf{S}(\mathbf{k g} / \mathbf{m})} \mathbf{3}^{2}$ & $\mathbf{B}_{\mathbf{S}(\mathbf{m})}$ & $\mathbf{T}_{(\mathbf{4 H} / \mathbf{V} \mathbf{s})(\mathbf{S e c})}$ & $\mathbf{T}_{(\text {Numerical)(Sec) }}$ \\
\hline 1 & 150 & $1053 \mathrm{e}+5$ & 0.3 & 30 & 1800 & 1 & 0.8 & 0.80006401 \\
2 & 150 & $1053 \mathrm{e}+5$ & 0.3 & 30 & 1800 & 5 & 0.8 & 0.80006401 \\
3 & 150 & $1053 \mathrm{e}+5$ & 0.3 & 30 & 1800 & 10 & 0.8 & 0.80006401 \\
4 & 150 & $1053 \mathrm{e}+5$ & 0.3 & 30 & 1800 & 20 & 0.8 & 0.80006401 \\
5 & 150 & $1053 \mathrm{e}+5$ & 0.3 & 30 & 1800 & 40 & 0.8 & 0.80006401 \\
6 & 150 & $1053 \mathrm{e}+5$ & 0.3 & 30 & 1800 & 80 & 0.8 & 0.80006401 \\
7 & 150 & $1053 \mathrm{e}+5$ & 0.3 & 30 & 1800 & 160 & 0.8 & 0.80006401 \\
8 & 150 & $1053 \mathrm{e}+5$ & 0.3 & 30 & 1800 & 200 & 0.8 & 0.80006401 \\
9 & 150 & $1053 \mathrm{e}+5$ & 0.3 & 30 & 1800 & 300 & 0.8 & 0.80006401 \\
\hline
\end{tabular}



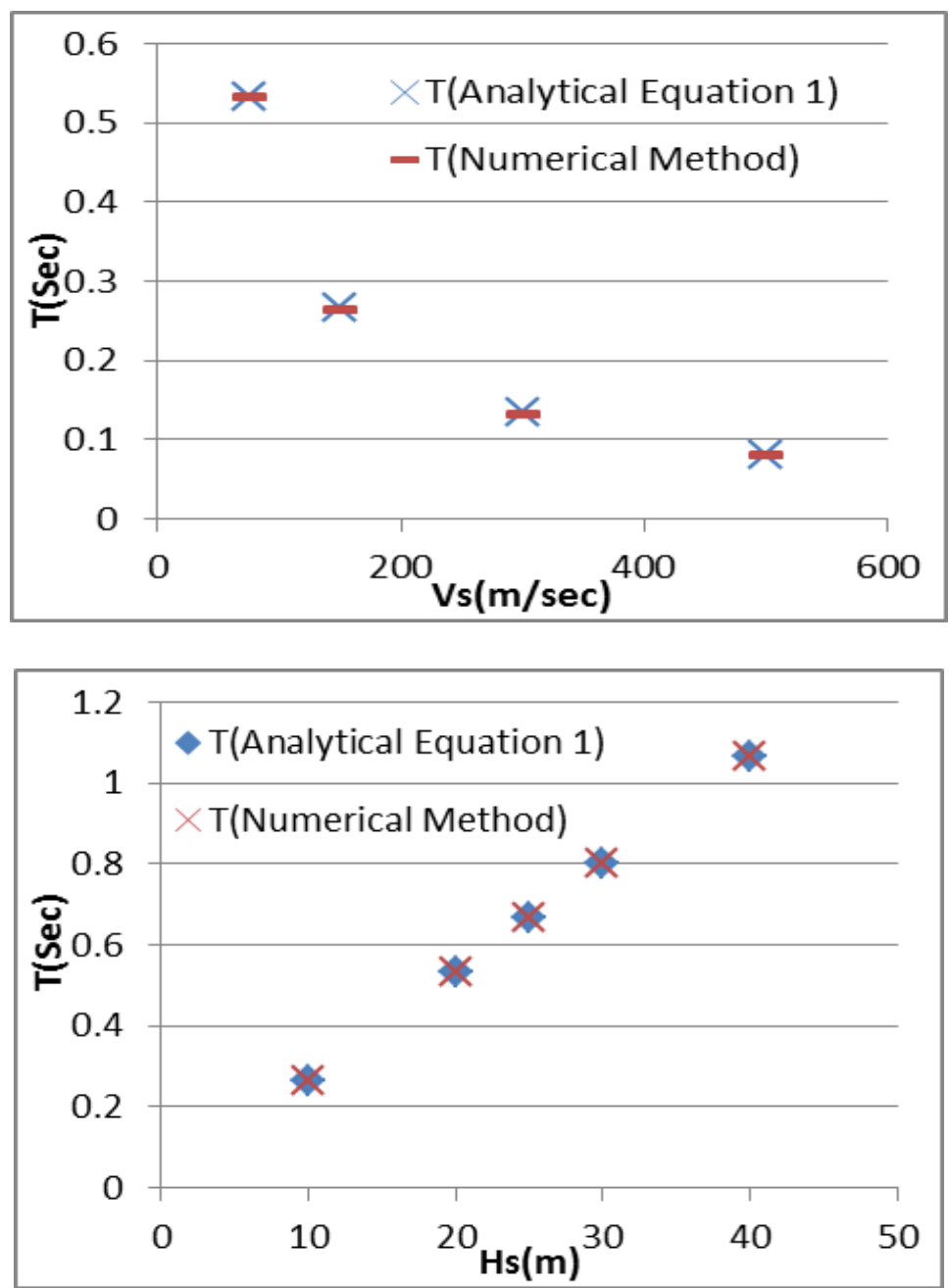

Figure 4: Comparison of the results obtained from the software and one dimensional analytical equation for different soil (Up), for various depths (Down)

Regarding an alluvium with fixed dimensions and material properties, the effects of adding piles with the specifications in Table 6 and equal intervals were investigated.This type of arrangement of pile is common in the construction of bridges foundation. In this 
study, this type of foundation was considered (limitation of the study). Molding has been conducted to a depth of 1 meter in the third dimension. Therefore, studies have been done to almost to a row of piles. Piles distance not considered in another dimension. Alluvium dimensions are considered constant and equal to $30^{m} \times 30^{m}$. The shear wave velocity of the soil layer is also considered constant and equal to $150^{\mathrm{m} / \mathrm{Sec}}$. As the piles are assumed to be implemented in a wide range on other dimensions, the modeling can be appropriately done via this method (2D). The main purpose of this study was to evaluate horizontal vibration of the system, so this type of boundary condition was selected. Also, the boundary conditions in the models are Y symmetric. It is assumed that the soil and the pile have the same behavior in the vibration (Tie Element).

As indicated in Figure 5, by adding piles to alluvial soil, the value of free vibration period increases and the results become different from the analytical equation (1).

Therefore, it can be concluded that in sediments in which piles are inserted (numerous piles), free vibration period is different from the period of the free vibration of an alluvial soil in the absence of piles, and this should be considered early in the seismic design of constructions.

Table 6. Characteristics of pile materials added to the alluvial $\operatorname{soil}\left(B_{S}=30^{n}, H_{S}=30^{m}\right)$

\begin{tabular}{c|ccccc}
\hline Characteristics & $\begin{array}{c}\mathrm{L}_{(\mathrm{m})} \\
\text { Length }\end{array}$ & $\begin{array}{c}\mathrm{D}_{(\mathrm{m})} \\
\text { Diameter }\end{array}$ & $\begin{array}{c}\mathrm{S}_{(\mathrm{m})} \\
\mathrm{Space}\end{array}$ & $\begin{array}{c}\mathrm{E}_{(\mathrm{N} / \mathrm{m})}^{2} \\
\text { Modulus of } \\
\text { elasticity }\end{array}$ & $\begin{array}{c}v \\
\text { Poisson's } \\
\text { ratio }\end{array}$ \\
\hline Concrete pile & 10 & 1 & 1 & $2 \mathrm{E}+10$ & 0.25 \\
\hline
\end{tabular}




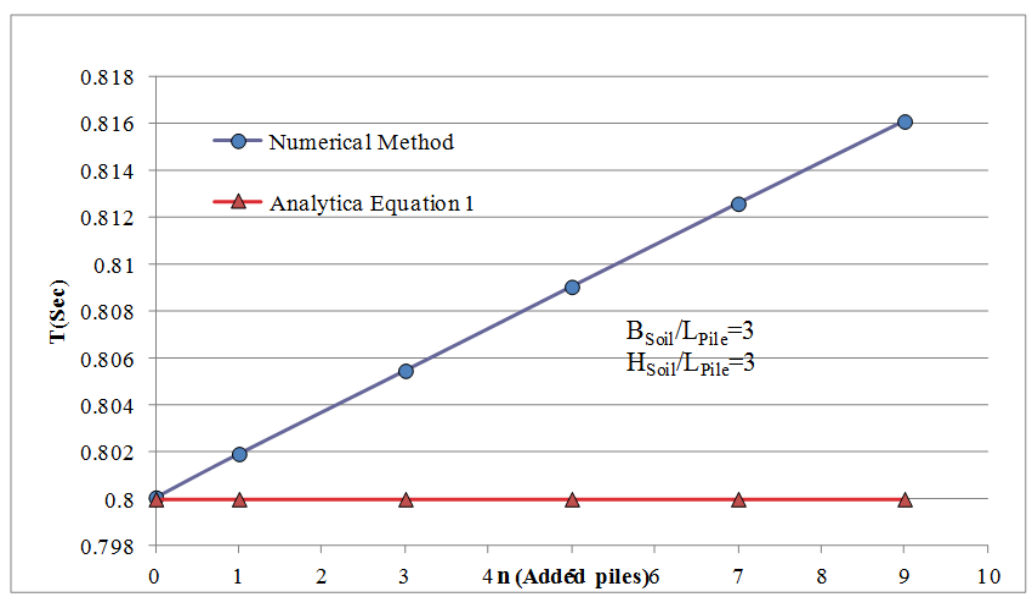

Figure 5. Comparison of the results of the software and the analytical equation (1) for the alluvial $\operatorname{soil}\left(B_{\text {Soil }}=30^{m}, H_{S o i l}=30^{m}\right)$ with different number of added piles.

In the following stage, extensive modeling studies are performed to evaluate the effect of different types of piles (in terms of friction and end-bearing piles) and different numbers on the free vibration period of an alluvium with fixed width and identical material characteristics. Since end-bearing pile is connected to a rigid layer, friction between the pile and the soil is negligible. And, because the floating pile is not connected to a rigid layer, the friction between the pile and the soil is significant.

For a better understanding of the process of changes, the difference between the results of the software and analytical equation 1 is provided as the following ratio, and the higher is the ratio, the more indicative of the effect of the piles. Figure 6 shows the results of the analysis (the effect of pile length to the depth of alluvium and number of added piles) of this part 
$E(\%)=\left(\frac{T_{\left(\frac{4 H}{V_{S}}\right)}-T_{(\text {Numerical })}}{T_{\left(\frac{4 H}{V_{S}}\right)}}\right) \times 100$

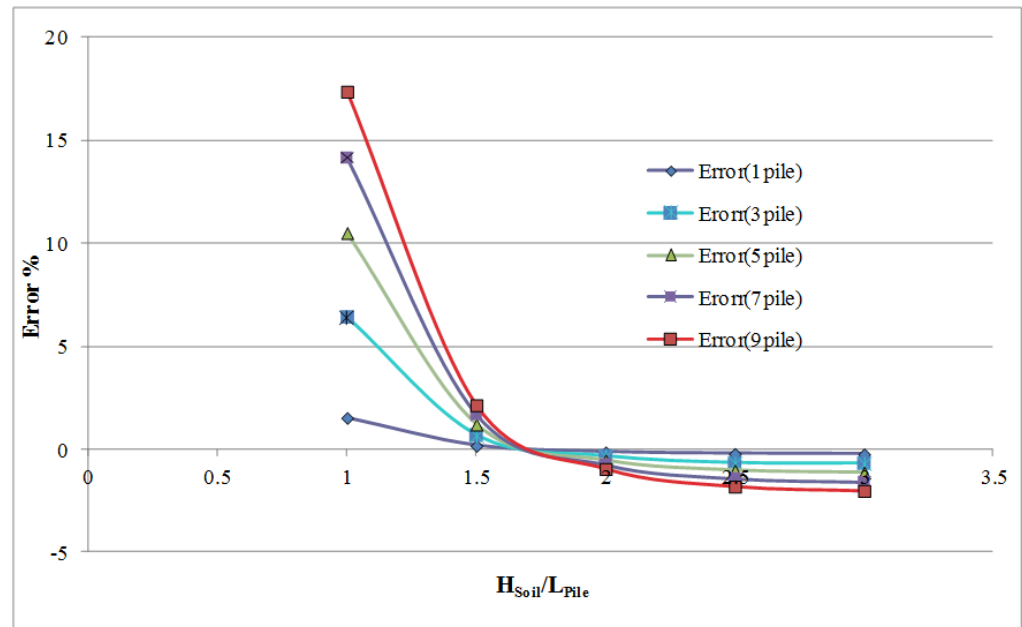

Figure6. Comparison of the results obtained from the software and one dimensional analytical equation for different floating ratio of the piles and different number of added piles

\section{Results and discussion}

Figure 6 shows that for a variety of pile length to height ratios of alluvial layer, different results for different number of piles are obtained, but with reduced ratio $\left(\frac{H_{S}}{L_{\text {Pile }}}\right)$, i.e. increased pile reinsurance, the effect of the piles increases. In other words, when the piles are end-bearing $\left(\frac{H_{S}}{L_{P i l}}=1\right)$, alluvium vibration period is more different than the non-reliance condition. The second point is that the increased number of piles affects the results with increased number of piles, and the results become more different (with respect to alluvium without piles).

For two reasons, piles change the vibration period of the soil layer: 
1. Concrete piles have more mass than the soil, and this increases the mass of the soil-pile system (end-bearing pile changes the mass in the entire layer, but floating pile changes the mass of system on top of the system).

2. Due to the placement of floating piles on the ground, stiffness of the soil-pile system changes less. But, stiffness of the system increases with the end-bearing piles.

Provided that the piles are end-bearing, the period of the system is less than the free field system, and if the piles are floating, the period of the system is greater than the free field state.

To further explore the issue, modeling was done with the assumption that the alluvium height, material characteristics, and number of piles are constant $(n=9)$, and only the width of alluvium and pile height $\left(\frac{B_{S}}{L_{P \text { ive }}}\right)$ changed. As shown in Figure 7, with increase in rates, the errors decrease; however, the errors are not significant.

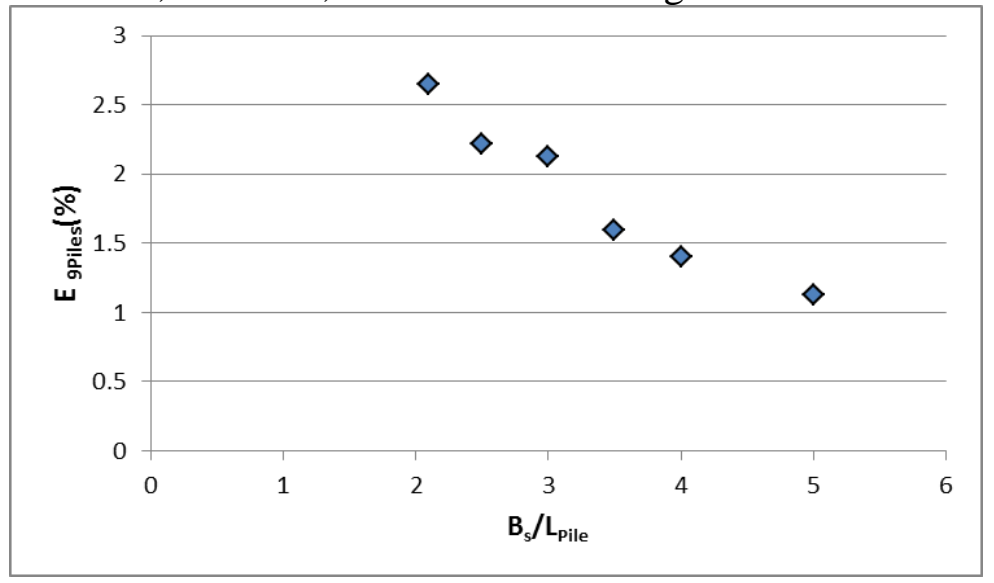

Figure 7. The difference of results (E) for different ratio of the alluvial soil width and the number of fixed added piles ( 9 piles) 


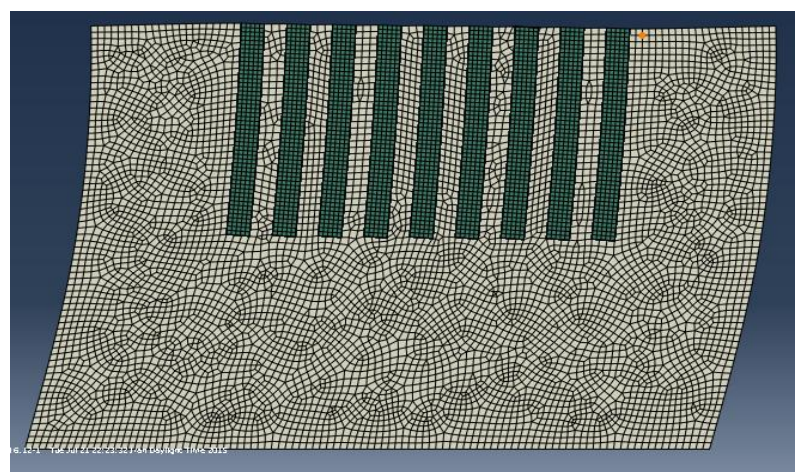

Figure 8. View of alluvium with (floating) piles modeled in numerical modeling

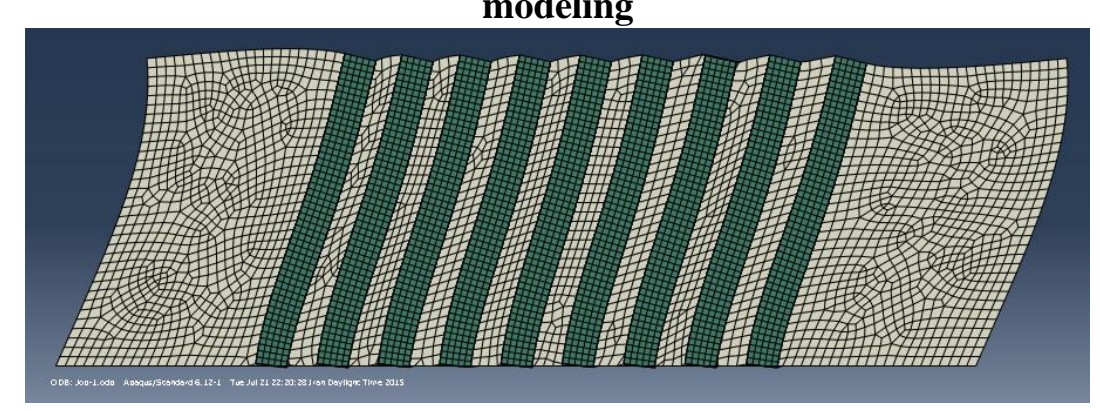

Figure 9: View of alluvium with (end-bearing) piles modeled in numerical modeling

\section{Conclusion}

In general, the results of numerical analysis could be presented as the following:

1. The results of numerical modeling, to calculate the period of the free vibration of alluvial soil, are not sensitive to the alluvial width, and as one-dimensional analytic equation, it depends solely on the alluvial height and construction materials. 
2. In the sediments in which (numerous) piles are inserted, vibration-free period is different from the period of the free vibration of alluvial soil without piles, which should be considered early in the seismic design of constructions.

3. If the piles are end-bearing, period of the system is less than the free field system, and if the piles are floating, period of the system is greater than the free field state.

4. With more end-bearing piles, the effects of piles on the change of alluvial soil vibration period increase. In other words, when the piles are end-bearing, alluvium vibration period becomes longer than non-friction condition (for models in this study; $17 \%$ difference can be seen).

5. Increasing the number of piles affects alluvial soil vibration period, and with increased number of piles, the vibration period of alluvial soil differs more than the condition without piles.

\section{References}

1. Kramer S. L., "Geotechnical earthquake engineering", New Jercey: Prentice Hall (1996).

2. Khoshnudian F., "Behavior of group piles under seismic loading", Iran (Islamic Republic of), s.n. (06 May2002 _ 08 May2002).

3. Kamatchi P., Rajasankar J., Iyer N., Lakshmanan N., Ramana G., Nagpal A., "Effect of depth of soil stratum on performance of buildings for sitespecific earthquakes", Soil Dynamics and Earthquake Engineering, Issue 30 (2010) 647-661. 
4. Rovithis E.N., Parashakis H., Mylonakis G.E., "1D harmonic response of layered inhomogeneous soil: Analytical investigation", Soil Dynamics and Earthquake Engineering, Issue 31(2011) 879-890.

5. Stamatopoulos C. A., "Effect of preloading on the amplification characteristics of soil profiles", Soil Dynamics and Earthquake Engineering, Issue 65 (2014) 189-205.

6. Sawada S., "A Simplified equation to approximate natural period of layered ground on the elastic bedrock", Vancouver B.C., Canada, 13th World Conference on Earthquake Engineering (2004).

7. Chenaria A., Taherib A., Davoodi M., "Uncertainty in fundamental natural frequency estimation for alluvial deposits", Computational Methods in Civil Engineering, 3(1) (2012) 77-94.

8. Ruiz S., Saragoni G.R., "Free vibration of soils during large earthquakes. Soil Dynamics and Earthquake Engineering, Issue 29 (2009) 1-16.

9. Hadjian A., "Fundamental period and mode shape of layered soil profiles", Soil Dynamics and Earthquake Engineering, Issue 22 (2002) 885-891.

10. Vrettos C., "Dynamic response of soil deposits to vertical SH waves for different rigidity depth-gradients", Soil Dynamics and Earthquake Engineering, Issue 47 (2013) 41-50.

11. Shirgir V., Ghanbari A., Shahrouzi M., "Natural Frequency of Single Pier Bridges Considering Soil-Structure Interaction", Journal of Earthquake Engineering, DOI:10.1080/13632469.2015.1104754 (2015).

12. Building and Housing Research Center, "Iranian Seismic Design Code for Structures",Tehran,Iran: s.n. (2000). 